\title{
Exposing the cuing task: the case of gaze and arrow cues
}

\author{
Dana A. Hayward • Jelena Ristic
}

Published online: 25 March 2015

(C) The Psychonomic Society, Inc. 2015

\begin{abstract}
The prevailing theoretical accounts of social cognitive processes propose that attention is preferentially engaged by social information. However, empirical investigations report virtually indistinguishable attention effects for social (e.g., gaze) and nonsocial (e.g., arrow) stimuli when a cuing task is used. Here, we show that this discrepancy between theory and data reflects a difference in how the extraneous processes induced by the cuing task's parameters (i.e., tonic alertness and voluntary temporal preparation) modulate cuespecific attentional effects. Overall, we found that tonic alertness and voluntary temporal preparation interacted within the cuing task, resulting in underadditive magnitudes of spatial orienting and superadditive magnitudes of the foreperiod effect. However, those interactions differentially affected social and nonsocial attention. While typical rapid social orienting was resilient to changing task parameters, sustained social orienting was eliminated only when the contribution of both extraneous processes was reduced. In contrast, orienting elicited by nonsocial arrows grew in magnitude with the reduction of voluntary temporal preparation and was delayed by the joint reduction of tonic alertness and voluntary temporal preparation. Together, these data indicate that cue-specific attention effects are masked by task dynamics of the cuing paradigm and highlight a pivotal role of the cuing task parameters in both the measurement and the theoretical attribution of spatial attention effects.
\end{abstract}

Keywords Posner cuing paradigm - Social attention · Automated symbolic orienting · Tonic alertness · Voluntary temporal preparation

D. A. Hayward $(\bowtie) \cdot$ J. Ristic $(\bowtie)$

Department of Psychology, McGill University, 1205 Dr. Penfield

Ave, Montreal, QC H3A 1B1, Canada

e-mail: dana.hayward@mail.mcgill.ca

e-mail: jelena.ristic@mcgill.ca

\section{Introduction}

It has been repeatedly found that social (e.g., gaze direction) and nonsocial (e.g., arrow direction) cues elicit spatial orienting. Participants shift their attention in the direction of eyes and arrows even when these cues do not reliably indicate the location of an upcoming target (Driver et al., 1999; Friesen \& Kingstone, 1998; Frischen, Bayliss, \& Tipper, 2007; Gabay, Avni, \& Henik, 2012; Langton \& Bruce, 1999; Pratt \& Hommel, 2003; Ristic, Wright, \& Kingstone, 2007). Despite the abundance of studies showing this result, two key issues about the measured attentional effects remain unresolved. The first concerns the difference between attentional orienting engaged by social and nonsocial stimuli. Although prevailing theoretical views maintain that due to evolutionary history orienting engaged by social information might be distinct from orienting engaged by nonsocial information (BaronCohen, 1995; Birmingham, Ristic, \& Kingstone, 2012; Nation \& Penny, 2008), the majority of investigations have so far failed to support this notion experimentally, finding equivalent attentional effects across the two cue types (Brignani, Guzzon, Marzi, \& Miniussi, 2009; Kuhn \& Kingstone, 2009; Stevens, West, Al-Aidroos, Weger, \& Pratt, 2008; Tipper, Handy, Giesbrecht, \& Kingstone, 2008; Tipples, 2008). The second issue concerns the implicated attentional control, as the data remain equivocal on the issue of whether attentional orienting elicited by social and nonsocial cues involves involuntary (Friesen \& Kingstone, 1998; Posner, 1980) or voluntary attention (Jonides, 1981; Tipples, 2008). Consequently, a meaningful integration of the data obtained with social and nonsocial cues within the prevailing theoretical accounts of attentional control has been hampered (Bonato, Priftis, Marenzi, \& Zorzi, 2008; Gibson \& Kingstone, 2006; Klein \& Shore, 2000).

To address these two questions, instead of resorting to analyses of the characteristics of orienting profiles as a function of 
cue type and/or cue predictiveness (Brignani et al., 2009; Friesen, Ristic, \& Kingstone, 2004; Galfano et al., 2012; Kuhn \& Kingstone, 2009), we investigated how the processes engaged by the parameters of the cuing task - tonic alertness and voluntary temporal preparation - affected orienting elicited by social and nonsocial information. The reasons for this manipulation are twofold. The first is that inducing high tonic alertness and engaging voluntary temporal preparation, as is typical for the cuing procedure, may differentially influence cue-specific effects on attention. While the attentional effects of social cues may be driven by high evolutionary salience (e.g., noticing a person in a room), irrespective of a particular task or response requirement, the attentional effects of nonsocial cues may depend on the task environment, especially those that promote links between goal-directed actions and response behaviors (e.g., following an arrow sign to exit). The second reason for this manipulation is that the executive processes engaged by the cuing task's parameters (Nieuwenhuis \& de Kleijn, 2013; Weinbach \& Henik, 2011, 2013) may differentially interact with cue-specific orienting depending on the nature of the required attentional control (e.g., involuntary vs. voluntary). That is, while involuntary attention should be unaffected by concurrent executive processes, voluntary attention should interact with them (Hayward \& Ristic, 2013b; Jonides, 1981).

\section{Orienting to Social and Nonsocial Cues}

Using a central face that displays task-irrelevant deviated gaze, numerous studies conducted so far have found that participants respond faster for gazed-at or cued relative to not gazed-at or uncued targets. This effect, which is thought to reflect the engagement of attention due to the social significance of gaze, emerges quickly by $100 \mathrm{~ms}$ post cue and persists up to 700-1000 ms (Driver et al., 1999; Friesen \& Kingstone, 1998; Langton \& Bruce, 1999) without inhibition (Greene, Mooshagian, Kaplan, Zaidel, \& Iacoboni, 2009; McKee, Christie, \& Klein, 2007).

A major caveat in interpreting these data as capturing the fundamentals of a social cognitive process lies in the result indicating that attentional effects observed with gaze cues in a cuing task are indistinguishable from attentional effects produced by a range of comparison nonsocial cues, including arrows (Brignani et al., 2009; Kuhn \& Kingstone, 2009), digit magnitude (Dodd, Van der Stigchel, Leghari, Fung, \& Kingstone, 2008), and words with spatial meaning (Hommel, Pratt, Colzato, \& Godijn, 2001). In contrast to the socio-evolutionary explanation, this finding suggests that orienting engaged by social cues may reflect a general mechanism for orienting in response to directional information rather than a specialized mechanism for facilitating the comprehension of socially relevant content.
Intuitively, however, social and nonsocial information serve different communicative purposes in life. Social signals, such as eye gaze or head direction, may be intrinsically alerting as they provide information about another person's interest or emotional involvement in a shared environment (Bateson, Nettle, \& Roberts, 2006; Csibra, 2010; Emery, 2000). As such, social information may engage attention rapidly, irrespective of current task or immediate overt response requirements. This is supported by data showing that social information is both prioritized and attended more frequently than nonsocial information when instead of a cuing task attention is measured using naturalistic looking behavior, i.e., using a procedure that does not require a specific response. That is, participants preferentially and rapidly fixate eyes and faces in complex images depicting everyday situations and attend to social cues more frequently overall relative to nonsocial cues (Birmingham, Bischof, \& Kingstone, 2009; Birmingham \& Kingstone, 2009; Boggia \& Ristic, 2014; Kuhn, Tatler, \& Cole, 2009). While not specifically indicating that differences in spatial orienting may exist between social and nonsocial cues, this body of evidence supports the idea that social and nonsocial information might be utilized differently in life, and further indicates that social information is prioritized over nonsocial information in complex everyday environments.

In contrast, nonsocial symbolic information affects attention automatically because of overlearned associations between the symbol's typical meaning and a particular response (Feigenson, Dehaene, \& Spelke, 2004). For example, digit magnitude is known to produce a "number line" effect in cultures who read from left to right (Dehaene, Bossini, \& Giraux, 1993), whereby the perception of small numbers (e.g., 1 and 2) leads to faster response times to targets on the left versus targets on the right side of fixation (Fischer, Castel, Dodd, \& Pratt, 2003; Ristic, Wright, \& Kingstone, 2006). Recent data indicate similar outcomes for directional symbols like arrows. Specifically, these studies show that the attentional effects elicited by symbolic arrows reflect automated symbolic attention, a type of attentional control that develops with overlearning the contingencies that exist between common symbols and typical responses (Ristic \& Kingstone, 2012; Ristic \& Landry, 2015; Ristic, Landry, \& Kingstone, 2012).

Thus, while the results from the cuing task have so far failed to reveal unique effects of social information on attention, other evidence suggests that social and nonsocial cues may engage attention in fundamentally different ways due to the typical usage of such information in everyday life (see also Kingstone, Friesen, \& Gazzaniga, 2000).

\section{Dissecting Social and Nonsocial Orienting Using a Cuing Task}

There are at least three reasons for why it is important to understand the potential limitations of the cuing task in 
revealing cue-specific attentional effects. First, the cuing paradigm is a classic procedure that has served as an experimental backbone for eliciting, measuring, and characterizing shifts of spatial attention for several decades now (Corbetta \& Shulman, 2002; Hopfinger, Buonocore, \& Mangun, 2000; Luck et al., 1994; Posner, 1980). Second, most of the current knowledge about spatial orienting elicited by social and nonsocial cues comes from investigations that have utilized the cuing task (Bayliss \& Tipper, 2006; Driver et al., 1999; Friesen et al., 2004; Frischen et al., 2007; Hayward \& Ristic, 2013b; Langton \& Bruce, 1999; Tipples, 2002, 2008). Finally, the data produced by this task have been instrumental in establishing the prevailing theoretical division between involuntary and voluntary attentional control (Berger, Henik, \& Rafal, 2005; Folk, Remington, \& Johnston, 1992; Jonides, 1981; Posner \& Cohen, 1984).

The cuing task In the typical cuing procedure, participants are presented with an attentional cue that indicates a possible target location in an area of space (Posner, 1980). After a varying cue-target interval (typically between 100-1000 ms), a target demanding a response is presented at either the spatial location indicated by the cue (i.e., cued target) or at some other location (i.e., uncued target). The effects of attention are revealed by the facilitation of responses for cued relative to uncued targets.

However in addition to spatial orienting, this typical task sequence engages two additional processes - tonic alertness and voluntary temporal preparation-whose effects on the resultant measurements of spatial orienting have not been systematically considered until very recently (Gabay \& Henik, 2008, 2010; Hayward \& Ristic, 2013a). Studying how these two processes in isolation and in conjunction affect orienting elicited by social and nonsocial cues provides a way to address the two outstanding issues regarding the nature of the attentional effects elicited by social and nonsocial information.

Specifically, due to evolutionary history, social information may inherently be alerting as well as non-reliant on a specific response. As such, its attentional effects should be resilient to variations in the task parameters that invoke changes in participants' overall readiness to respond (i.e., tonic alertness) and those that promote task-specific contingencies between the cue and the target (i.e., voluntary temporal preparation). In contrast, automated effects of nonsocial arrows reflect an overlearned coupling between the cue and a specific response event (i.e., a target). As a result, changes in the task parameters that modify such expectancies may in turn modulate orienting elicited by nonsocial cues like arrows.

Tonic alertness Tonic alertness reflects an overall readiness to respond (Callejas, Lupiáñez, Funes, \& Tudela, 2005). One way to manipulate tonic alertness in a cuing task is to alter the proportion of trials in which the target appears following the cue. High tonic alertness is achieved by presenting a target on most trials (e.g., on $95 \%$ of trials; Näätänen, 1972). This creates a strong link between the presentation of the cue and the appearance of a target, and produces faster overall RTs (Correa, Lupiànez, Milliken, \& Tudela, 2004; Posner \& Boies, 1971). Low tonic alertness, on the other hand, is achieved by presenting a target on fewer trials overall (e.g., on $75 \%$ of trials; Alegria, 1978; Näätänen, 1972). This weakens the link between the presentation of the cue and the appearance of a target, and results in the overall slowing of RTs (Alegria, 1978; Näätänen, 1972; Tipper \& Kingstone, 2005).

Modulating tonic alertness experimentally will reveal the extent to which this process affects social and nonsocial orienting. Given the hypothesized intrinsic alerting quality of social information, this manipulation should not affect social orienting; however lowering tonic alertness may act to delay the emergence of spatial orienting elicited by nonsocial arrows, as presumably nonsocial cues do not embody high alerting power.

Voluntary temporal preparation Voluntary temporal preparation reflects the participants' voluntary entrainment to the timing of events within each trial (Coull, Frith, Buchel, \& Nobre, 2000; Miniussi, Wilding, Coull, \& Nobre, 1999; Mondor, 1999; Näätänen, 1972; Nobre, 2001). The discrete sequence of short, intermediate, and long cue-target intervals (e.g., 100, 300, 600, $900 \mathrm{~ms}$ ) that are typically used in a cuing procedure lead to the development of implicit voluntary expectancies about when, within each trial a target is most likely to occur (Coull et al., 2000). This is because even though an equal number of targets are normally assigned to appear at each cue-target interval, the probability of target occurrence increases with increasing cue-target time (see Methods and Fig. 3 Quadrants 1 and 3 for more details). This manipulation reflects the so-called "aging" distribution (Gabay \& Henik, 2008,2010 ), engages implicit voluntary entrainment, and results in a robust foreperiod effect (as indexed by an overall shortening of RTs with the lengthening of cue-target time; Bertelson, 1967).

To illustrate a typical aging distribution, consider the following example. In an experiment with four cue-target intervals and 544 trials, 32 of which are no-target trials, 128 trials are assigned to each cue-target interval (i.e., (544-32)/4). The probability of target occurrence at the shortest cue-target interval is thus $128 / 544$, or $23 \%(p=0.23)$. However, if no target appears at this shortest cue-target time, the probability of target occurrence at the next successive cue-target time jumps to $31 \%(p=0.31 ; 128 /(544-128))$, as the number of remaining trials decreases by how many previous cue-target intervals did not contain a target. Thus, for the longest cue- 
target interval, the probability of target occurrence reaches $80 \%(p=0.8 ; 128 /(544-384))$.

Within a cuing task, temporal entrainment can be modulated by altering the frequency and consequently the probability of target occurrence at each cue-target interval. When instead of assigning an equal number of targets to each cue-target interval the number of targets is halved for each successive cue-target time, the probability of target occurrence at each cue-target interval remains constant (see Methods and Fig. 3, Quadrants 2 and 4). This manipulation reflects the so-called "non-aging" distribution (Gabay \& Henik, 2008, 2010; Näätänen, 1972), results in the elimination of implicit voluntary entrainment, and leads to the disappearance of the foreperiod effect (Gabay \& Henik, 2008; Näätänen, 1972).

Modulating temporal entrainment will reveal the extent to which social and nonsocial orienting is aided by the temporal links between the cue and the target. Orienting elicited by nonsocial arrows is hypothesized to be sensitive to the taskrelevant relationship between the cue and the target. Consequently, eliminating the implicit temporal contingency may result in a reduction of orienting magnitudes elicited by nonsocial cues. In contrast, social orienting should remain resilient to changes in those cue-target links.

\section{The Present Study}

We examined how changes in tonic alertness and voluntary temporal preparation affect the two typical measures produced by the cuing task - spatial orienting and the foreperiod effect. Figure 1 shows our $2 \times 2$ design. Tonic alertness was either (i) high, with the target occurring in $94 \%$ of trials (Gabay \& Henik, 2008; Hayward \& Ristic, 2013a) or (ii) low, with the target occurring in $75 \%$ of trials (Tipper \& Kingstone, 2005). Voluntary temporal preparation was either (i) present, with implicit temporal entrainment induced by the task (e.g., aging distribution; Näätänen, 1972) or (ii) absent, with implicit temporal entrainment eliminated (e.g., non-aging distribution; Gabay \& Henik, 2008, 2010; Näätänen, 1972).

Thus, Quadrant 1 mirrored the design of all past studies that have investigated orienting elicited by gaze and arrows using the cuing task so far (Driver et al., 1999; Friesen \& Kingstone, 1998; c.f., Okamoto-Barth \& Kawai, 2006) with high tonic alertness and present voluntary temporal preparation. Consequently, we expected to replicate their results showing equivalent attention effects across gaze and arrow cues (Ristic, Friesen, \& Kingstone, 2002; Tipples, 2002).

In Quadrants 2 and 3, the individual contributions of voluntary temporal preparation (Quadrant 2) and tonic alertness (Quadrant 3) were reduced. If tonic alertness and voluntary temporal preparation affect spatial orienting in an independent manner, we expected no modulations of social orienting in either condition and a reduction in the magnitude of nonsocial orienting when voluntary temporal preparation was absent.
Tonic Alertness

\begin{tabular}{|c|c|c|}
\hline & $\begin{array}{c}\text { High } \\
\text { (94\% Target) }\end{array}$ & $\begin{array}{c}\text { Low } \\
\text { (75\% Target) }\end{array}$ \\
\hline 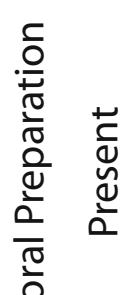 & $\begin{array}{l}\text { Quadrant 1: } \\
\text { Tonic Alertness } \\
\& \\
\text { Voluntary } \\
\text { Temporal } \\
\text { Preparation }\end{array}$ & $\begin{array}{c}\text { Quadrant 3: } \\
\\
\text { Voluntary } \\
\text { Temporal } \\
\text { Preparation }\end{array}$ \\
\hline 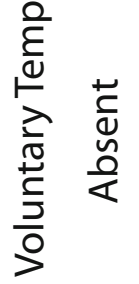 & $\begin{array}{l}\text { Quadrant 2: } \\
\text { Tonic Alertness }\end{array}$ & Quadrant 4: \\
\hline
\end{tabular}

Fig. 1 Design matrix. Quadrant 1 denotes high tonic alertness and present voluntary temporal preparation (i.e., Tonic Alertness and Voluntary Temporal Preparation); Quadrant 2 denotes high tonic alertness and absent voluntary temporal preparation (i.e., Tonic Alertness); Quadrant 3 denotes low tonic alertness and present voluntary temporal preparation (i.e., Voluntary Temporal Preparation); Quadrant 4 denotes low tonic alertness and absent voluntary preparation (i.e., None)

One might also predict that nonsocial orienting may be delayed under reduced tonic alertness, as nonsocial cues may not be as intrinsically alerting.

Finally, in Quadrant 4, the contributions of both tonic alertness and voluntary temporal preparation were reduced. If social and nonsocial cues exert cue-specific attentional effects, we expected to observe their dissociation in this condition because here the measure of attentional orienting is devoid of all extraneous task influences. Furthermore, differences in spatial orienting between the two cues in Quadrant 4 would also indicate interactions between tonic alertness and voluntary temporal preparation, suggesting that the cuing task does not reflect a pure measure of spatial orienting, but rather a measure of attention that is contaminated by the interactions between these extraneous processes.

\section{Experiment 1}

Methods

\section{Participants}

A total of 120 participants were recruited, with $30(\mathrm{~N}=30)$ randomly assigned to each cue type (gaze vs. arrow) and tonic alertness (high vs. low) condition. 


\section{Apparatus \& Stimuli}

The stimuli and an example trial sequence are shown in Fig. 2. As in past studies (Friesen \& Kingstone, 1998; Friesen et al., 2004; Ristic \& Kingstone, 2006), black and white line drawings of a schematic face (Fig. 2A) and an arrow (Fig. 2B), presented at central fixation, served as cues. The face consisted of an outline $\left(9.4^{\circ}\right)$, pupils (i.e., black filled-in circles centered within eye outlines; $\left.0.7^{\circ}\right)$, mouth $\left(3^{\circ}\right)$, and a nose $\left(0.3^{\circ}\right)$. The arrow consisted of a horizontal line $\left(4.6^{\circ}\right)$ with an arrowhead and an arrow tail (each $1.9^{\circ}$ ). The target was a capital letter ' $X$ ' $\left(1^{\circ}\right)$, which appeared with an eccentricity of $6.4^{\circ}$ away from central fixation. The stimuli were shown on a 16-in CRT monitor at an approximate distance of $57 \mathrm{~cm}$.

\section{Design}

Cue type (gaze vs. arrow) and tonic alertness (high vs. low) were between-subjects variables and were presented in a blocked fashion. Voluntary temporal preparation (present vs. absent), cue validity (cued vs. uncued), and cue-target interval were within-subjects variables. Voluntary temporal preparation was blocked and presented in a random order between participants while cue validity and cue-target interval were intermixed and presented in a pseudorandom fashion within participants. ${ }^{1}$ On any given trial, gaze and arrow cues indicated either a left or right spatial location, and the targets appeared on either the left or right side. All cue direction and target location combinations were equally likely, thus gaze and arrow cues were spatially uninformative.

Figure 3 shows the independent manipulations of tonic alertness and voluntary temporal preparation.

Tonic alertness Tonic alertness was manipulated by altering the number of trials in which a target appeared following the presentation of the cue, which was shown on every trial (Tipper \& Kingstone, 2005). In the high tonic alertness condition (Fig. 3, Quadrants 1 and 2), the target was present in $94 \%$ of trials (i.e., $6 \%$ no-target trials). In the low tonic alertness condition (Fig. 3, Quadrants 3 and 4), the target was present in $75 \%$ of trials (i.e., $25 \%$ no-target trials).

Voluntary temporal preparation Voluntary temporal preparation was manipulated by changing the number of targets assigned to appear at each cue-target interval (Gabay \& Henik, 2008; Näätänen, 1970, 1972).

\footnotetext{
${ }^{1}$ The order of voluntary temporal preparation condition presentation did not influence the orienting effects. An omnibus mixed effects ANOVA with voluntary temporal preparation order (present first vs. present second), tonic alertness, and cue type included as between-subjects variables, and voluntary temporal preparation, cue validity, and cue-target interval included as within-subjects variables returned no reliable effects involving cue validity and order (all Fs $<3.1$, all ps $>0.08$ ).
}

Voluntary temporal preparation was present when the target assignment followed the aging distribution (Fig. 3, Quadrants 1 and 3). This resulted in an increased probability of target occurrence with lengthening of cue-target time (Hayward \& Ristic, 2013a). For the high alertness case, 128 targets were assigned to each cue-target interval, whereas 32 trials contained no target, resulting in a total of 544 trials (Fig. 3, Quadrant 1). The probability that a target would occur at the shortest cue-target interval of $100 \mathrm{~ms}$ was $23 \%$ ( $p=$ $0.23 ; 128 / 544$ trials). However, as the cue-target interval lengthened, the probability of target occurrence increased, reaching $80 \%$ ( $p=0.8 ; 128 / 160$ trials) for the longest cuetarget interval of $925 \mathrm{~ms}$. As outlined before, this increasing probability reflects the changing ratio between the fixed number of trials that are assigned to occur at each cue-target time and the number of remaining trials, which decreases systematically with the passage of each cue-target interval that receives no target. For the low tonic alertness case, 120 targets were assigned to each cue-target interval and 80 trials contained no target, resulting in a total of 320 trials. Thus, the probability of target occurrence was $23 \%(p=0.23$; $120 / 320$ total trials) at the shortest cue-target interval of $100 \mathrm{~ms}$ and $60 \%$ at the longest cue-target interval of $925 \mathrm{~ms}$ ( $p=0.6 ; 120 / 200$ remaining trials).

Voluntary temporal preparation was absent when the target assignment followed the non-aging distribution, which equates the probability of target appearance across the cuetarget intervals. This is accomplished by halving the number of targets allocated to appear at each successive cue-target interval (Fig. 3, Quadrants 2 and 4) (Gabay \& Henik, 2008; Hayward \& Ristic, 2013a). In contrast to the aging distribution, here the ratio between the number of trials that contain the target at each successive cue-target time and the number of remaining trials remains unchanged, as both parameters decrease systematically.

The non-aging distribution was implemented differently for the high and low tonic alertness conditions. This was necessary because the probability of target presence within trials is determined both by the number of trials that contain a target and the number of individual cue-target intervals. Mathematically, to create the high tonic alertness condition with $94 \%$ target presence and to equate the target probability across cue-target intervals to $50 \%(p=0.5)$, one must utilize exactly four cue-target times (i.e., 100, 375, 650, and $925 \mathrm{~ms}$ ). Here, 256 targets were presented at the shortest cue-target interval of $100 \mathrm{~ms} ; 128$ targets were presented at the cuetarget interval of $375 \mathrm{~ms}$; 64 targets were presented at the cue-target interval of $650 \mathrm{~ms}$, and 32 targets were presented at the cue-target interval of $925 \mathrm{~ms}$. The target was not shown in 32 trials, leading to $94 \%$ target present trials. Similarly, to create the low tonic alertness condition with $75 \%$ target presence and to equate the target probability across cue-target intervals, one must use exactly two cue-target times. Here, 


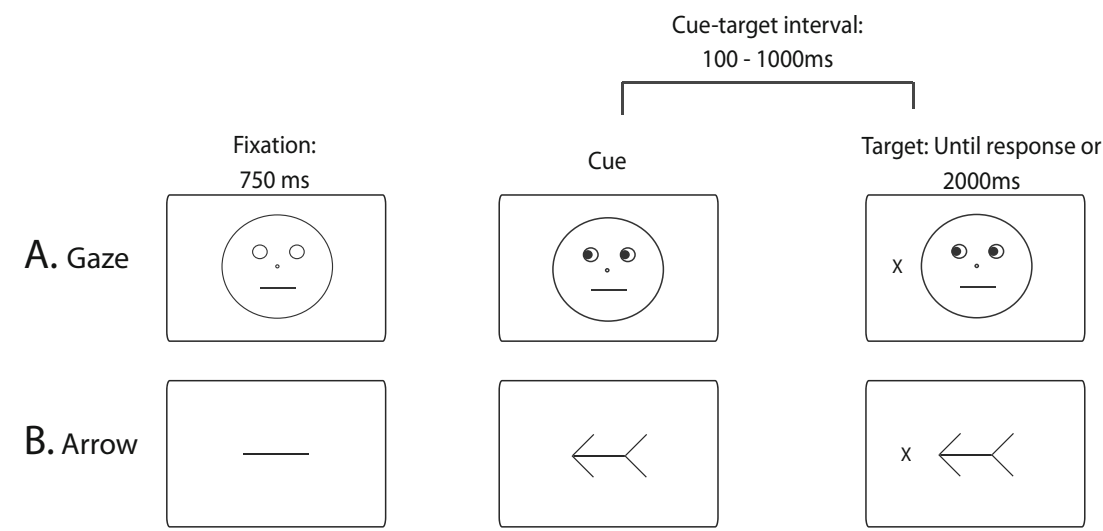

Fig. 2 Example stimulus sequence. At the beginning of each trial, a fixation screen with either a blank face (A) or a horizontal line (B) was shown for $750 \mathrm{~ms}$. Next, pupils or an arrow, indicating either a left or right location, were presented. After a variable cue-target interval the target

160 trials were presented at the short cue-target interval of $100 \mathrm{~ms}$ and 80 trials were presented at the long cue-target interval of $925 \mathrm{~ms}$. The target was not shown in 80 trials, leading to $75 \%$ target present trials.

Quadrant 1: Alertness \& Temporal Preparation

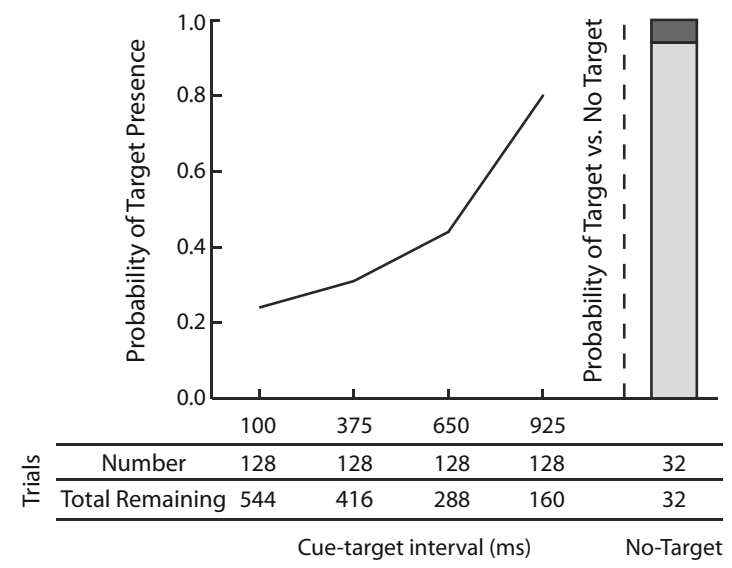

Quadrant 2: Alertness

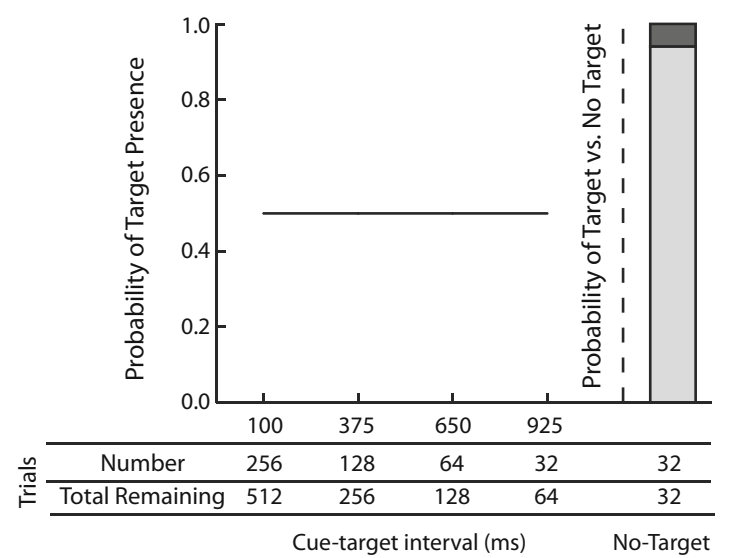

letter " $\mathrm{X}$ " appeared on either the left or right side. The cue and target remained on the screen until a response was made or until $2000 \mathrm{~ms}$ had elapsed. Note: The stimuli are not drawn to scale

It is important to note that the present manipulations of tonic alertness and voluntary temporal preparation in a fully crossed manner forced the utilization of uneven numbers of cue-target intervals (4 cue-target intervals in Quadrants 1 and

Quadrant 3: Temporal Preparation

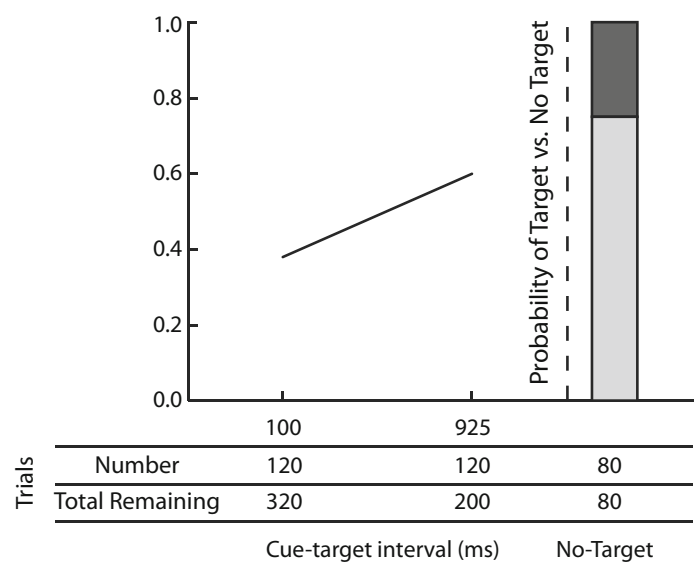

Quadrant 4: None

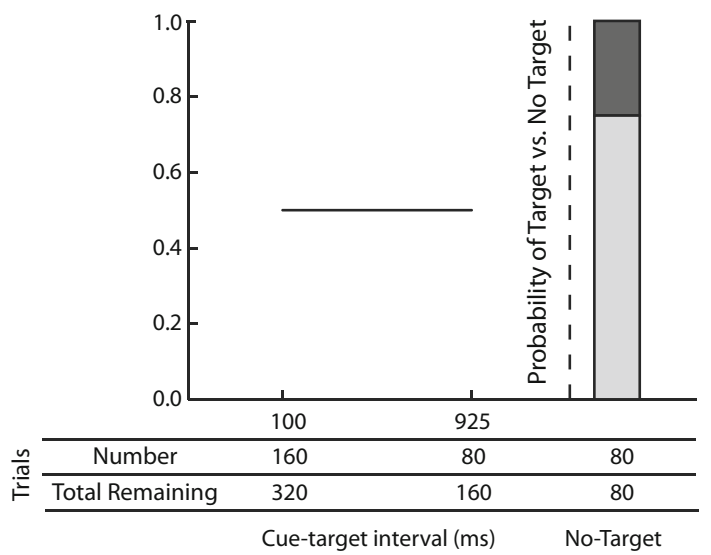

Fig. 3 Manipulations of tonic alertness and voluntary temporal preparation. The probability of target presence (y-axis) is plotted for each design quadrant along with the corresponding numerical depiction of the number of targets assigned to each cue-target interval (x-axis) 
2 vs. 2 cue-target intervals in Quadrants 3 and 4) and a differential strength of implicit temporal expectancy ( $80 \%$ likelihood of target presence at the longest cue-target time in Quadrant 1 vs. $60 \%$ likelihood of target presence at the longest cue-target time in Quadrant 3) across conditions. Despite this, our data firmly argue against the alternative interpretation that these parameter differences determined our results. That is, and as reported in the Results section, we found no overall differences in orienting for both cue types between the high and low tonic alertness conditions, which differed both in the number of cue-target intervals and the strength of implicit temporal expectancy. Furthermore, all results held with analyses that accounted for these design variations (see Results, Footnotes 2 and 4 ). ${ }^{2}$ Therefore, the necessity of the present design did not systematically influence our data.

\section{Procedure}

Each trial began with the presentation of either a blank face (2A, Friesen \& Kingstone, 1998) or a straight line (2B, Ristic \& Kingstone, 2006, 2012) for $750 \mathrm{~ms}$. Then, pupils looking left or right or an arrow pointing left or right appeared. After the variable cue-target interval, the target appeared on either the left or right side of fixation and participants were instructed to press the spacebar as quickly and as accurately as possible once they detected its onset, and to withhold a response if no target appeared. ${ }^{3}$ The cue and the target remained on the screen until response or until $2000 \mathrm{~ms}$ had elapsed. RT was measured from target onset, participants were informed that the direction of the cue did not predict the location of the target, and five practice trials were run at the start.

\section{Results}

Response errors were low, with anticipations (RT $<100 \mathrm{~ms}$ ) and timeouts (RT $>1000 \mathrm{~ms}$ ) accounting for less than $1.8 \%$ in

\footnotetext{
2 To examine whether the changes in the strength of temporal predictability across the design Quadrants influenced our results, we conducted an omnibus ANOVA in which we equated the probability of late target appearance for Quadrant 1 to the probability of late target appearance for Quadrant $3(\mathrm{p}=0.6)$. To do so, we averaged the RTs from the third cue-target interval in Quadrant $1(\mathrm{p}=0.44)$ with the RTs from the fourth cue-target interval from that same quadrant $(p=0.8)$. Averaging was performed for cued and uncued trials separately. This provided an estimate of RTs when the probability of target appearance at the longest cuetarget time was $62 \%(\mathrm{p}=0.62 ;(0.44+0.80) / 2)$ in Quadrant 1 and consequently closely approximated the probability of target appearance at the longest cue-target interval in Quadrant $3(60 \% ; p=0.6)$. The results fully replicated the omnibus ANOVA reported in the Results section.

${ }^{3}$ Although there has been some evidence to suggest that the experimental manipulation of voluntary temporal preparation affects attentional orienting only during discrimination tasks (see Gabay \& Henik, 2008, 2010; Milliken, Lupiáñez, Roberts, \& Stevanovski, 2003 for a more indepth discussion), we recently showed that changes in tonic alertness and voluntary temporal preparation also affect attentional orienting during detection tasks (Hayward \& Ristic, 2013a).
}

any condition. False alarms (i.e., responding on a no-target trial) did not exceed $2.7 \%$ in any condition. Mean correct RTs were analyzed at the common cue-target intervals of $100 \mathrm{~ms}$ and $925 \mathrm{~ms}$, which was the only way to fully and directly compare modulations in spatial orienting as a function of all four conditions, i.e., tonic alertness and voluntary temporal preparation. ${ }^{4}$

An omnibus mixed effects ANOVA was used. Cue type (gaze vs. arrow) and tonic alertness (high vs. low) were between-subjects variables. Voluntary temporal preparation (present vs. absent), cue validity (cued vs. uncued), and cuetarget interval (100 and $925 \mathrm{~ms}$ ) were within-subjects variables.

We first report and discuss the effects involving spatial orienting (i.e., those relating to cue validity). Then, we report the effects involving the foreperiod effect (i.e., those relating to cue-target interval). Finally, we test for independence between tonic alertness and voluntary temporal preparation by applying the additive factors logic (Sternberg, 1969).

\section{Spatial Orienting}

To remind, we hypothesized that social orienting would remain unaffected by changes in tonic alertness and voluntary temporal preparation. We also hypothesized that the magnitude of spatial orienting elicited by nonsocial arrows might be reduced when voluntary temporal preparation was eliminated

\footnotetext{
${ }^{4}$ The same data pattern held if, instead of analyzing the data from the common cue-target intervals, we analyzed the data including all cuetarget intervals. Because this necessitates a different analysis approach, we ran two mixed-effects ANOVAs, one for the high alertness group, which contained all cue-target intervals, i.e., 100, 375, 650, and $925 \mathrm{~ms}$, and one for the low alertness group, which contained two cuetarget intervals, i.e., 100 and $925 \mathrm{~ms}$. Both analyses included cue type (gaze vs. arrow) as a between-subjects variable, and voluntary temporal preparation (present vs. absent), cue validity (cued vs. uncued), and cuetarget interval as within-subjects variables. In the high alertness group, participants overall responded faster to cued relative to uncued targets $[\mathrm{F}(1,58)=65.4, \mathrm{p}<0.001]$, with this difference growing with lengthening of cue-target interval [cue validity $\mathrm{x}$ cue-target interval; $\mathrm{F}(3,174)=5.2$, $\mathrm{p}$ $<0.01$ ] and when voluntary temporal preparation was absent [cue validity $\mathrm{x}$ voluntary temporal preparation; $\mathrm{F}(1,58)=4.7, \mathrm{p}<0.05$; all other effects involving cue validity and cue type; Fs $<2$, all ps $>0.1$ ]. Thus, orienting effects of social and nonsocial cues did not differ under conditions of high tonic alertness. In contrast, the effects for the two cues diverged under low tonic alertness. In this case although participants were once again faster to respond to cued as compared to uncued targets $[\mathrm{F}(1,58)=18.0, \mathrm{p}<.001]$, two interactions involving cue type and cue validity emerged. The first was a three-way interaction between cue type, cue validity and cue target interval $[\mathrm{F}(1,58)=7.8, \mathrm{p}<.01]$ and the second one was a four-way interaction between cue type, voluntary temporal preparation, cue validity and cue target interval $[\mathrm{F}(1,58)=5.0, \mathrm{p}<.05]$. The first interaction mirrors our finding indicating that orienting to arrow cues grew with the lengthening of cue-target time, while orienting to gaze cues decreased with the lengthening of cue-target time. The second (four-way) interaction is the same interaction reported in the Results section. Thus, the data were the same regardless of whether the analyses included the common cue-target intervals or all cue-target intervals.
} 
and that its effects may be delayed with lowering of tonic alertness. Finally, we reasoned that any cue-specific effects of gaze and arrow cues would be revealed in Quadrant 4, in which both tonic alertness and voluntary temporal preparation were reduced. Interparticipant mean correct RTs and the magnitudes of orienting (i.e., uncued RT - cued RT) are plotted in Fig. 4 as a function of cue type, tonic alertness, voluntary temporal preparation, cue validity, and cue-target interval.

Overall, orienting was reliable, with an RT advantage for cued targets $(\mathrm{F}(1,116)=44.0, p<0.001)($ Friesen \& Kingstone, 1998; Ristic et al., 2002). Orienting effects diverged across cue type as a function of voluntary temporal preparation and cue-target interval only [cue type $\mathrm{x}$ voluntary temporal preparation $\mathrm{x}$ cue validity $\mathrm{x}$ cue-target interval, $\mathrm{F}(1$, 116) $=4.3, p<0.05$; other interactions involving cue type and cue validity Fs $<1.5, p \mathrm{~s}>0.2]$. Changes in tonic alertness alone, on the other hand, did not reliably modulate orienting [cue type $\mathrm{x}$ tonic alertness $\mathrm{x}$ cue target interval $\mathrm{x}$ cue validity, $\mathrm{F}<1$; cue type $\mathrm{x}$ tonic alertness $\mathrm{x}$ cue validity, $\mathrm{F}<1$; all other interactions involving tonic alertness, cue validity, and cue

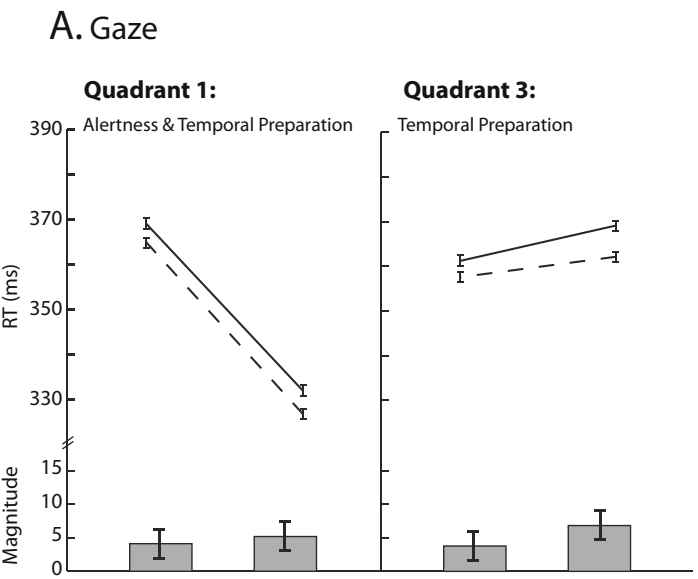

type, all $\mathrm{Fs}<3$, all $p \mathrm{~s}>0.05]$. On the whole, the magnitudes of spatial orienting grew with increasing cue-target time [cue validity $\mathrm{x}$ cue-target interval, $\mathrm{F}(1,116)=5.7, p<0.05]$, and especially for arrows [cue type $\mathrm{x}$ cue validity $\mathrm{x}$ cue-target interval, $\mathrm{F}(1,116)=9.2, p<0.01]$ with the largest overall magnitudes of orienting observed in Quadrant 2 [tonic alertness $\mathrm{x}$ voluntary temporal preparation $\mathrm{x}$ cue validity, $\mathrm{F}(1,116)$ $=4.7, p<0.05]$. Note that although the five-way interaction between all variables was not reliable, both the presence of a four-way interaction between cue type, voluntary temporal preparation, cue validity and cue-target interval as well as our a priori hypotheses about the divergence of cue type effects in Quadrant 4 warrant a closer examination of orienting under present and absent voluntary temporal preparation conditions as well as within Quadrant 4 itself.

As the omnibus ANOVA indicated that cue type effects diverged as a function of voluntary temporal preparation and cue-target interval, we next ran two additional mixed effects ANOVAs, conducted separately for present voluntary temporal preparation (Quadrants 1 and 3) and absent voluntary

\section{B. Arrow}

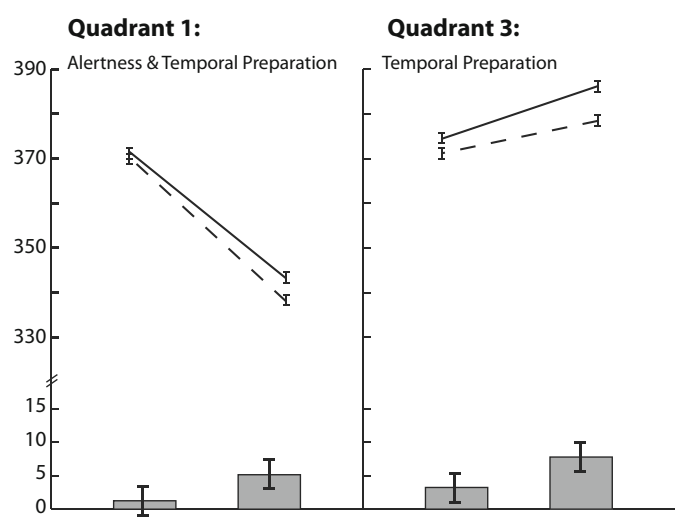

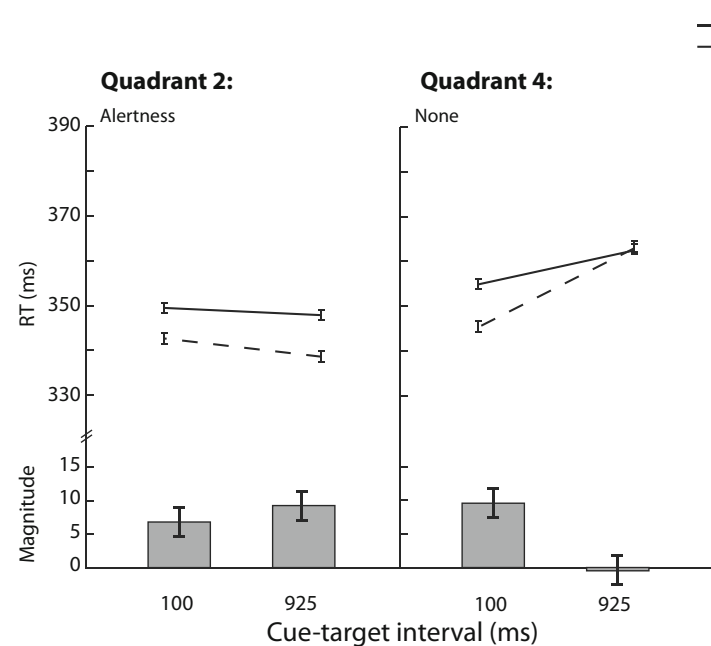

Fig. 4 Experiment 1 results. Mean correct RTs and magnitudes of orienting (uncued RT - cued RT) are shown as a function of cue validity (cued vs. uncued) and cue-target interval (100 ms and $925 \mathrm{~ms}$ )
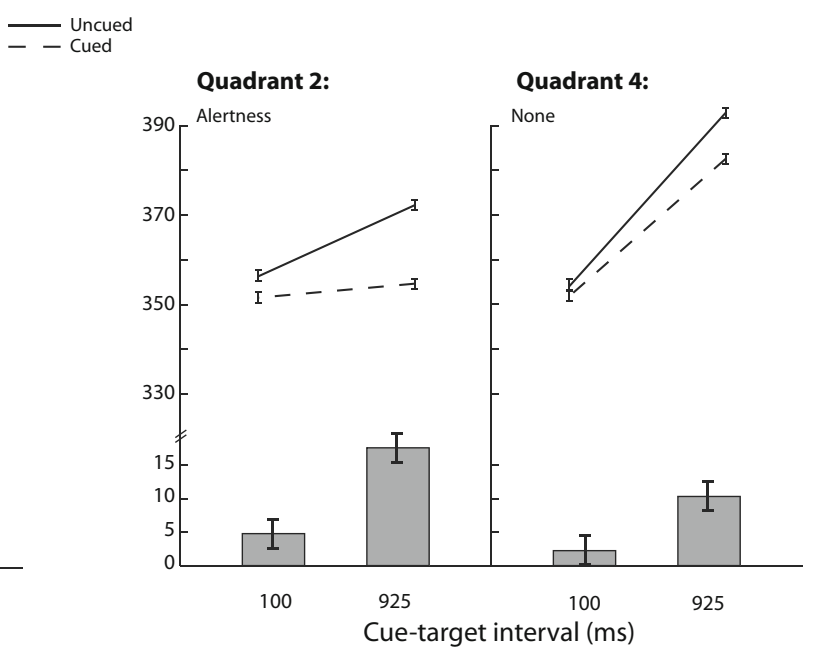

for Gaze (A) and Arrow (B) cues. The data are plotted for each of the four experimental conditions for each cue type. Error bars represent the standard error of the difference between the means 
temporal preparation conditions (Quadrants 2 and 4). Each analysis was run as a function of cue type, cue validity, and cue target interval.

When voluntary temporal preparation was present, spatial orienting [cue validity; $\mathrm{F}(1,118)=19.5, p<0.001$ ] did not vary with either cue type or cue-target interval (cue type $\mathrm{x}$ cue validity; cue validity $\mathrm{x}$ cue-target interval; cue type $\mathrm{x}$ cue validity $\mathrm{x}$ cue-target interval, all $\mathrm{Fs}<3$, all $p \mathrm{~s}>0.05$; all other effects $\mathrm{Fs}<2.1$, all $p \mathrm{~s}>0.1$ ), indicating that orienting elicited by gaze and arrow cues did not diverge under conditions of present voluntary temporal preparation.

In contrast, when voluntary temporal preparation was absent, spatial orienting [cue validity; $\mathrm{F}(1,118)=39.6, p<$ 0.001 ] interacted with cue type and cue-target interval [cue type $\mathrm{x}$ cue validity $\mathrm{x}$ cue-target interval; $\mathrm{F}(1,118)=11.3, p<$ 0.01 ; all other effects $\mathrm{Fs}_{\mathbf{s}}<3, p \mathrm{~s}>0.05$ ]. This indicates that with lengthening of cue target time, orienting elicited by arrows increased in magnitude while orienting elicited by gaze decreased in magnitude. Furthermore, as illustrated in Fig. 4, this data pattern was especially pronounced in Quadrant 4, which we hypothesized was the condition in which cue-specific effects of social and nonsocial cues would be revealed. In fact, when we contrasted cue type effects for each Quadrant, using separate mixed effects ANOVAs run as a function of cue type, cue validity, and cue-target interval, we found a reliable divergence between orienting effects of social and nonsocial cues in Quadrant 4 only $^{5}$ [cue validity $\mathrm{F}(1,58)=13.6, p<0.001$; cue type $\mathrm{x}$ cue validity $\mathrm{x}$ cue-target interval $\mathrm{F}(1,58)=13.5, p<$ 0.001 ; all other effects involving cue validity $\mathrm{Fs}<2$, all $p \mathrm{~s}>$ $0.2]$.

Thus, in line with our hypotheses, social orienting remained relatively unaffected by our manipulations; however, the typical sustained effect was eliminated in Quadrant 4 with the reduction of both extraneous processes. In contrast, orienting elicited by arrows increased in magnitude with lengthening cue-target time when voluntary temporal preparation was absent, and furthermore was delayed with a reduction of both tonic alertness and voluntary temporal preparation in Quadrant 4. We return to these findings in the Discussion.

Together, the data for spatial orienting suggest that the processes invoked by tonic alertness and voluntary temporal preparation interact within the cuing task, and that those interactions affect orienting elicited by social and nonsocial cues differently. Namely, while social orienting was modulated only when both tonic alertness and voluntary temporal preparation were reduced, orienting elicited by nonsocial arrows was modulated by changes in voluntary temporal preparation

\footnotetext{
$\overline{5}$ The same mixed-effects ANOVA, with cue type as the between-subjects variable and cue validity and cue-target interval as within-subjects variables was also run for the remaining three quadrants. Although there were main effects of cue validity in all three cases (all Fs $>7.0$, all ps $<0.05$ ), no interactions between cue type and cue validity were observed (all $\mathrm{Fs}<$ 2.5 , all ps $>0.1$.
}

alone, as well as by joint changes in tonic alertness and voluntary temporal preparation.

\section{Foreperiod Effect}

Next, we examined the effects of changing tonic alertness and voluntary temporal preparation on the foreperiod effect. First, replicating previous data and verifying the effectiveness of our manipulations, we observed the expected modulations of participants' overall response speed and the magnitude of the foreperiod effect with changes in the task parameters (Callejas, Lupiáñez, \& Tudela, 2004; Gabay \& Henik, 2008; Hayward \& Ristic, 2013a; Näätänen, 1972).

Participants were overall slower to respond to targets under low relative to high tonic alertness $(\mathrm{F}(1,116)=4.1, p<0.05$; Gabay \& Henik, 2008; Näätänen, 1972). Lowered tonic alertness (tonic alertness $\mathrm{x}$ cue-target interval, $\mathrm{F}(1,116)=52.5, p<$ 0.001 ) (Tipper \& Kingstone, 2005) and absent voluntary temporal preparation (voluntary temporal preparation $\mathrm{x}$ cue-target interval, $\mathrm{F}(1,116)=138.8, p<0.001)$ (Gabay \& Henik, 2008) individually and jointly (tonic alertness $\mathrm{x}$ voluntary temporal preparation $\mathrm{x}$ cue-target interval, $\mathrm{F}(1,116)=22.7, p<0.001$ ) (Hayward \& Ristic, 2013a) modulated the foreperiod effect. The typical foreperiod effect, as illustrated in Fig. 4, with fastest responses for targets at the longest cue-target interval, was observed only when tonic alertness was high and voluntary temporal preparation was present in Quadrant 1, while the most pronounced decline in its magnitude was observed when both processes were experimentally reduced in Quadrant 4 (Correa, Lupiàñez, \& Tudela, 2006; Hayward \& Ristic, 2013a). In line with our finding showing a larger susceptibility of spatial orienting elicited by arrows to changes in voluntary temporal preparation, the foreperiod effect elicited by arrows showed a more pronounced decline overall [cue type $\mathrm{x}$ cuetarget interval; $\mathrm{F}(1,116)=7.0, p<0.01$; cue type $\mathrm{x}$ voluntary temporal preparation $\mathrm{x}$ cue-target interval; $\mathrm{F}(1,116)=6.8, p<$ 0.05 ; all other effects involving cue-target interval $\mathrm{Fs}<3, p \mathrm{~s}>$ $0.05]$.

Thus, the foreperiod effect, which reflects the strength of implicit target expectancy induced by the task, declined in magnitude with individual and joint changes in tonic alertness and voluntary temporal preparation, and especially when nonsocial arrows served as fixation stimuli. Furthermore, the foreperiod effect even appeared "reversed" in Quadrant 4 in that slowest overall RTs were observed for the longest cuetarget time with the reduction of both extraneous processes. This finding likely reflects the largest task-related reduction in target expectancy with changes in task-mediated cue-target contingencies (see also Hayward \& Ristic, 2013a for a similar result), and indicates that the foreperiod effect is sensitive to fluctuations in one's overall readiness to respond (i.e., tonic alertness; see also Tipper \& Kingstone, 2005) and to changes 
in the task-induced expectancies (i.e., voluntary temporal preparation; see also Gabay \& Henik, 2008).

\section{Relationship between Tonic Alertness and Voluntary Temporal Preparation}

On the whole then, the results for both spatial orienting and the foreperiod suggest that tonic alertness and voluntary temporal preparation interact in a cuing paradigm. To test this notion, we analyzed their independence. If the two processes were independent, the data from the condition in which both processes are present (i.e., Quadrant 1; high tonic alertness and present voluntary temporal preparation) should approximate the additive sum of the data from the combination of their individual components (Quadrant 2 (Tonic Alertness) + Quadrant 3 (Voluntary Temporal Preparation)). Our analyses of the magnitudes of spatial orienting and the foreperiod did not support this independence account.

Figure $5 \mathrm{~A}$ shows that the sum of orienting magnitudes (uncued RT - cued RT) for gaze and arrow cues for Quadrants 2 and 3 was always larger than the magnitude of orienting in Quadrant 1 (Gaze: $\mathrm{t}(88)=-3.26, p<0.01$; Arrow: $\mathrm{t}(88)=-20.1, p<0.001$, unpaired, two-tailed).

Figure $5 \mathrm{~B}$ illustrates the corresponding data for the foreperiod effect. In sharp contrast to the orienting data, the magnitude of the foreperiod effect (Mean $\mathrm{RT}_{100 \mathrm{~ms}}-$ Mean $\mathrm{RT}_{925 \mathrm{~ms}}$ ) decreased as the contributions of tonic alertness and voluntary temporal preparation were reduced. The sum of the foreperiod magnitudes for gaze and arrow cues for
Quadrants 2 and 3 was always smaller than the magnitude of the foreperiod effect in Quadrant 1 (Gaze: $\mathrm{t}(88)=9.2, p<$ 0.001; Arrow: $\mathrm{t}(88)=7.3, p<0.001$; unpaired, two-tailed).

As these analyses illustrate, the effects of tonic alertness and voluntary temporal preparation in a typical cuing task are not independent. Rather, their interactions simultaneously affect the measures of both spatial orienting and the foreperiod effect in an opposing manner. While underadditive magnitudes of orienting are observed in the typical task when both tonic alertness and voluntary temporal preparation are present, superadditive magnitudes of the foreperiod emerge for this same condition.

\section{Discussion}

Experiment 1 revealed that task-related processes inherent in the cuing paradigm interact, with those interactions differentially modulating orienting elicited by social and nonsocial cues. Orienting elicited by nonsocial arrows increased in magnitude with the removal of an implicit temporal contingency between the cue and the target and was delayed when both tonic alertness and voluntary temporal preparation were reduced. In contrast, orienting elicited by social gaze was partially affected only when the contribution of both processes was reduced, in that early orienting remained unchanged, but the typical sustained effect was eliminated. Tonic alertness in isolation did not differentially affect spatial orienting across the two cue types. Additivity analyses further indicated that the smallest overall magnitudes of orienting were found under
A. Orienting

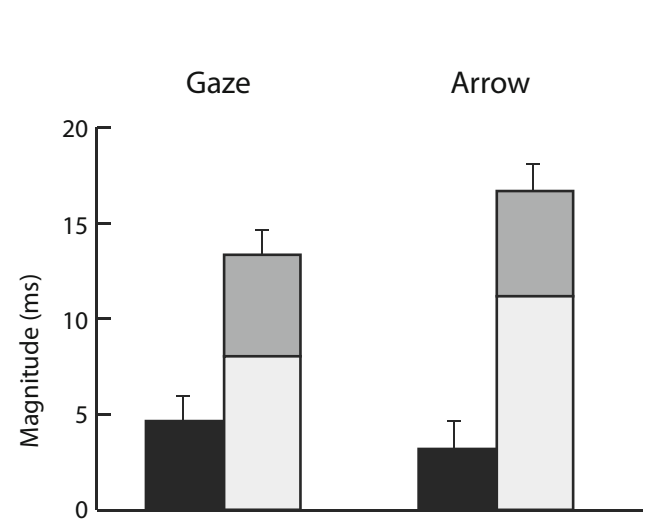

B. Foreperiod

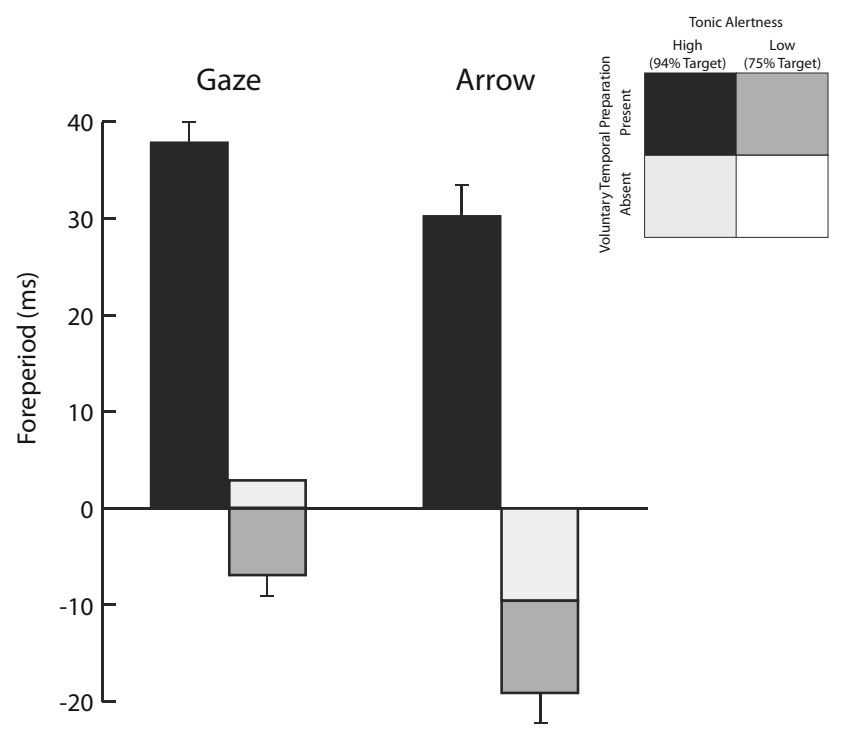

foreperiod effect (mean $\mathrm{RT}_{100 \mathrm{~ms}}-$ mean $\mathrm{RT}_{925 \mathrm{~ms}}$ ) as a function of cue type (Gaze vs. Arrow) for Quadrant 1 relative to the additive sum of foreperiod magnitudes for Quadrant 2 (Tonic Alertness) and Quadrant 3 (Voluntary Temporal Preparation). Error bars represent the standard error of the difference between the means
Fig. 5 Relationship between tonic alertness and voluntary temporal preparation. A Magnitudes of orienting (uncued RT - cued RT) as a function of cue type (Gaze vs. Arrow) for Quadrant 1 relative to the additive sum of orienting magnitudes for Quadrant 2 (Tonic Alertness) and Quadrant 3 (Voluntary Temporal Preparation). B Magnitudes of the 
the typical condition in which both tonic alertness and voluntary temporal preparation were present.

Interactions between tonic alertness and voluntary temporal preparation also emerged for the foreperiod effect. The typical foreperiod effect was observed only when tonic alertness was high and voluntary temporal preparation was present (Quadrant 1), whereas the most pronounced decline in its magnitude occurred when the contribution of both task parameters was reduced (Quadrant 4). Finally, and suggestive of the hypothesized links between task-related cue-specific attention effects, the most pronounced decline in the foreperiod magnitude was observed when arrows served as fixation stimuli.

In contrast to our initial hypothesis, however, the magnitude of nonsocial orienting increased with the removal of implicit temporal entrainment, i.e., voluntary temporal preparation. We reasoned that removing the task-relevant temporal links between the cue and the target would be detrimental to automated symbolic attention, which is hypothesized to depend on such task contingencies. Our data indicated the opposite, in that when implicit temporal preparation was eliminated, orienting elicited by arrows grew in magnitude at the late cue-target interval. Furthermore, when both tonic alertness and voluntary temporal preparation were reduced, nonsocial orienting was delayed.

One explanation for this result is that the removal of the temporal cue-target links may have freed up additional voluntary resources for automated orienting elicited by arrows. In turn, this would suggest that automated symbolic orienting might be under a degree of voluntary control. To investigate this possibility, we examined how changes in the magnitude of the foreperiod tracked with changes in the magnitude of orienting from the early to the late cue-target interval. If eliminating the task related cue-target links frees up cognitive resources for automated symbolic orienting, but leaves social orienting intact, we expected to find a divergence in the magnitudes of the foreperiod and orienting for arrows but not for gaze cues.

To capture the change in magnitudes of orienting and the foreperiod from the early to late cue-target interval and to bring the two measures to a common metric, we calculated percent rate of change for both measures. For orienting, this metric reflected the change in the magnitude of orienting from the early to the late cue-target interval. For the foreperiod, it reflected the change in speed of responding from the early to the late cue-target interval (i.e., foreperiod magnitude). These data are illustrated in Fig. 6, with positive values denoting an increase in foreperiod and orienting magnitudes, negative values denoting a decrease in magnitudes, and a value of zero denoting no change in magnitudes across cue-target times.

A mixed effects ANOVA with cue type (gaze vs. arrow; between-subjects), measure (orienting vs. foreperiod), and voluntary temporal preparation (present vs. absent; withinsubjects) returned a reliable three-way interaction between cue type, measure, and voluntary temporal preparation $[\mathrm{F}(1$, $118)=8.3, p<0.01]$. This interaction indicated that the magnitudes of orienting and foreperiod diverged for arrows but not for gaze cues under absent voluntary temporal preparation. That is, unlike social orienting which did not change with decreasing foreperiod, an increase in nonsocial orienting was accompanied by a sharp decline in the foreperiod magnitude. This suggests that the executive processes devoted to voluntary temporal preparation and those devoted to the maintenance of automated orienting interfere within a cuing task and compete for voluntary resources. The ANOVA also returned a main effect of voluntary temporal preparation $[\mathrm{F}(1,118)=57.1, p<0.001]$, reflecting an overall increase in magnitudes with present voluntary temporal preparation, and a two-way interaction between cue type and measure $[\mathrm{F}(1$, $118)=13.7, p<0.001$; all other all $\mathrm{Fs}<2$, all $p \mathrm{~s}>0.1$, once again indicating a divergence in magnitudes across social and nonsocial cues.

In sum, Experiment 1 showed that rapid orienting elicited by gaze remained robust, even when gaze direction provided no reliable spatial information about the location of the target, no reliable temporal information about when within a trial the target was most likely to occur, and was a less reliable signal for subsequent target appearance. In contrast, spatial orienting elicited by nonsocial arrows was affected by the removal of the implicit temporal link between the cue and the target in that it grew with the removal of executive processes needed to maintain this temporal contingency. Furthermore, delayed nonsocial orienting was observed with joint reductions in task aids of tonic alertness and voluntary temporal preparation in Quadrant 4.

\section{Experiment 2}

Although these conclusions are consistent with our data, one alternative interpretation is that the results showing resilient rapid social orienting may reflect the physical size difference between face and arrow stimuli. Specifically, because the gaze cue was embedded in a face outline, and the arrow cue was presented in isolation, the size of the face cue may have acted as a stronger alerting signal. A sensible approach to testing if the physical size of the stimulus determined the alerting effects of social cues would be to present the eyes in isolation and an arrow cue embedded within a circle outline.

There are two points worth considering here. The first one is that our data argue against this alternative, because stimulus sizes were constant across the Experiment 1 manipulations, whereas the differences between social and nonsocial attention effects emerged only with specific changes in tonic alertness and voluntary temporal preparation. The second point relates to the typical representation of gaze and arrow cues. One might argue that social signals, such as gaze, are 


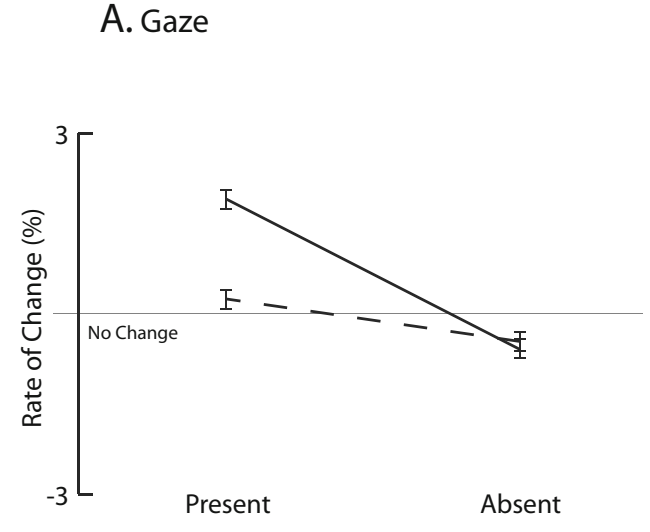

Voluntary Temporal Preparation

Fig. 6 Relationship between orienting and the foreperiod. Percent rate of change of magnitudes of orienting and the foreperiod from short to long cue-target interval, for Gaze (A) and Arrow cues (B). A positive value

intrinsically alerting precisely because they are an integral part of a human face, whose holistic organization includes the head contour, eyes, nose, and mouth. Presenting face-features in isolation may thus disrupt the typical social context of gaze information (Tanaka \& Farah, 1993). Along the same lines, adding a circle outline to an arrow cue may artificially imbue the arrow with a higher alerting value, due to the larger physical size. Thus, changes to the typical representations of social and nonsocial stimuli may equate their physical properties for experimental purposes; however, such manipulations may simultaneously put the two cues on unequal footing by stripping the gaze cue from its typical social context and artificially increasing the alerting value of nonsocial arrows.

To test the influence of cue size, in Experiment 2 we presented participants with a smaller eyes-only cue and a larger arrow cue embedded within a circle outline. If the face outline acted as a general alerting signal in Experiment 1, no rapid social orienting was expected for the eyes-only condition in Experiment 2.

\section{Methods}

\section{Participants, Apparatus, Stimuli, Design and Procedure}

Because cue-specific effects of gaze and arrow cues were observed only when tonic alertness was low and voluntary temporal preparation was absent in Quadrant 4, only this condition was run in Experiment 2. Sixty additional participants were recruited; 30 were assigned randomly to either the eyesonly or arrow condition. The task parameters were kept the same as in Experiment 1 except that: (1) The original gaze cue was altered to contain just eyes; and (2) The original arrow cue was altered by adding a circle outline measuring $11.3^{\circ}$ (Fig. 7).
B. Arrow

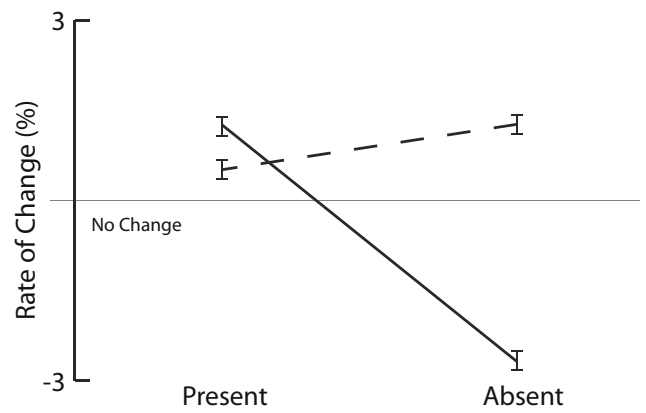

Voluntary Temporal Preparation

denotes an increase in magnitude, a negative value denotes a decrease in magnitude, and a value of zero denotes no change in magnitude. Error bars represent the standard error of the difference between the means

Results

First, we confirmed that there were no overall differences between Experiment 1 and Experiment 2 results. A mixed effects ANOVA was used with Experiment (Experiment 1 vs. Experiment 2) and cue type (eye gaze vs. arrow) included as between-subject variables, and cue validity (cued vs. uncued) and cue-target interval (100 and $925 \mathrm{~ms}$ ) included as within-subject variables. The results indicated no reliable interactions involving Experiment [Experiment $\mathrm{x}$ cue type $\mathrm{x}$ cue validity $\mathrm{x}$ cue-target interval; $\mathrm{F}(1,116)=2.3, p>0.1$; all other interactions with Experiment, all $\mathrm{Fs}<1.5$, all $p \mathrm{~s}>0.2$ ], while continuing to show the main effect of spatial orienting $[\mathrm{F}(1,116)=27.8, p<0.001]$ as well as the critical interaction between cue type, cue validity, and cue-target interval $[\mathrm{F}(1$, 116) $=9.9, p<0.01]$. Thus, overall Experiment 2 replicated Experiment 1.

To specifically inspect the influence of cue size, next we examined the Experiment 2 data separately with a mixed effects ANOVA run as a function of cue type (gaze vs. arrow; between-subject variable), cue validity (cued vs. uncued) and cue-target interval (100 and $925 \mathrm{~ms}$; within-subject variables). Main effects of spatial orienting $[\mathrm{F}(1,58)=14.3, p<0.001]$ and the foreperiod effect $[\mathrm{F}(1,58)=48.7, p<0.001]$ were reliable, with no interactions (all $\mathrm{Fs}<1.5, p \mathrm{~s}>0.2$ ). These results (Fig. 7A) show that rapid social orienting effects found in Experiment 1 (Fig. 7B) persisted in an equal manner in Experiment 2 even with the physically smaller eyes-only cue (Gaze: Fig. 7A vs. B; Experiment 2 and Experiment $1100 \mathrm{~ms}$ cue-target interval effects both ts $>-3.4, p$ s $<0.01$, two-tailed, paired). However, reliable rapid orienting also emerged for nonsocial arrows in Experiment 2, with an increase in arrow cue size (Arrows: Fig. 7A vs. B; Experiment 2100 ms cuetarget interval: $\mathrm{t}(29)=-3.3, p<0.01$; Experiment $1100 \mathrm{~ms}$ cue-target interval: $\mathrm{t}(29)<-1, p>0.35$, two-tailed, paired), 


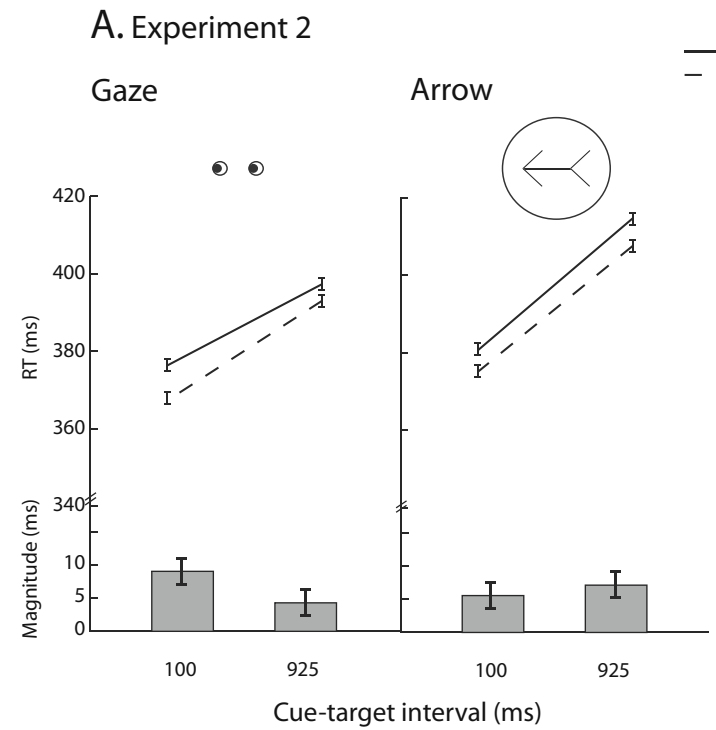

Fig. 7 Experiment 2 results. Mean correct RTs and magnitudes of orienting (uncued RT - cued RT) as a function of cue validity (cued vs. uncued) and cue-target interval (100 ms and $925 \mathrm{~ms}$ ) for gaze and arrow

indicating that the orienting effects elicited by the cuing task also are vulnerable to the changes in the nonsocial stimulus size properties.

\section{General Discussion}

We investigated the differences in attentional orienting elicited by social gaze and nonsocial arrow cues within the cuing paradigm by assessing the fate of orienting when the extraneous processes induced by this task - tonic alertness and voluntary temporal preparation - are systematically manipulated. Importantly, as we held the spatial contingency between the cue and the target at chance level, any divergence between orienting effects across social and nonsocial cues unambiguously reflected attentional modulations as a function of tonic alertness and voluntary temporal preparation. Overall, we found that the processes invoked by tonic alertness and voluntary temporal preparation interact within the cuing task and that those interactions affect the measures of orienting and the foreperiod elicited by social and nonsocial cues differently. Thus, at the most general level, these data indicate that attentional and preparatory (i.e., foreperiod) effects elicited by the cuing task are contaminated by interactions between the extraneous task parameters.

In the Introduction, we reasoned that the extraneous cuing task processes of tonic alertness and voluntary temporal preparation might affect orienting elicited by social and nonsocial cues within the cuing task differently for two reasons (Birmingham et al., 2009; Ristic \& Kingstone, 2012). First, because social information might be intrinsically more alerting due to its evolutionary importance, its typical effects
B. Experiment 1, Quadrant 4

Gaze

Arrow

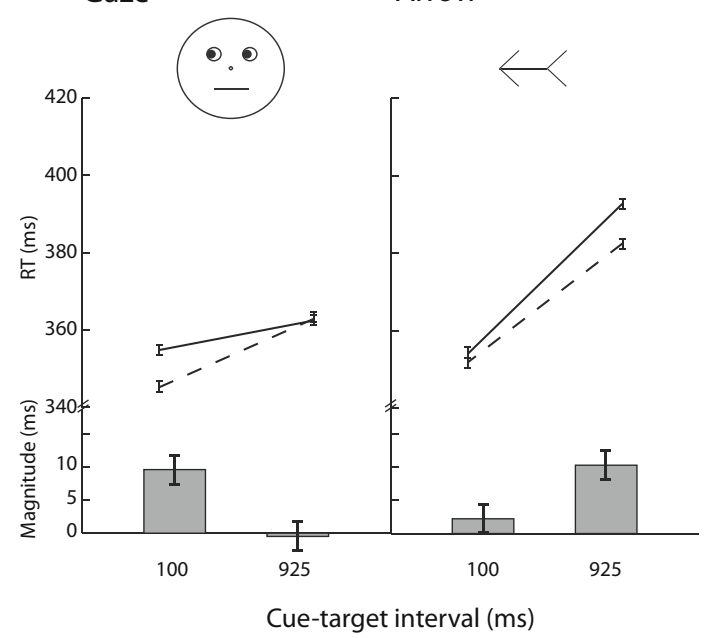

cues (A) in contrast to the same data from Experiment 1 (B). Error bars represent the standard error of the difference between the means. Note: The stimuli are not drawn to scale

on attention were expected to persist despite changes in task settings (Emery, 2000; Kobayashi \& Hashiya, 2011; Okamoto-Barth \& Kawai, 2006). Second, for arrows, recent findings indicating that orienting elicited by nonsocial symbolic cues reflect their utility for behavior (Ristic \& Kingstone, 2012) suggested to us that the attentional effects elicited by arrows might be especially susceptible to changes in the tasks' settings with regards to cue-target contingencies.

Experiment 1 revealed that when the cuing task parameters mirrored typical settings with high tonic alertness and present voluntary temporal preparation (Quadrant 1), attentional effects elicited by gaze and arrow cues did not differ (see footnote 5; Frischen et al., 2007). However, when we lowered tonic alertness and eliminated voluntary temporal preparation in isolation (Quadrants 2 and 3) and in conjunction (Quadrant 4), the attentional effects of gaze and arrows began to diverge. Gaze cues continued to produce rapid effects, while sustained orienting was absent only in Quadrant 4 when the contribution of both extraneous factors was reduced (i.e., under low tonic alertness and absent voluntary temporal preparation). In contrast, orienting elicited by arrows was affected by changes in voluntary temporal preparation alone and by a joint reduction in tonic alertness and voluntary temporal preparation. Surprisingly, and in contrast to our predictions, the removal of voluntary temporal preparation resulted in an increase rather than a decrease in the magnitude of nonsocial orienting. As we have argued, this result likely reflects an increased availability of voluntary, endogenous resources due to the removal of a concurrent voluntary process. Supporting the idea that nonsocial information is not alerting on its own, we also found that a joint reduction in tonic alertness and voluntary temporal preparation resulted in a delay of nonsocial orienting. In 
Experiment 2, we showed that changes to the size of the social gaze cue resulted in no modulations of early social orienting.

Our analyses of the foreperiod effect showed that the removal of tonic alertness and voluntary temporal preparation individually and in combination resulted in a decline of its magnitude, and especially so when arrows served as stimuli. Moreover, we found that interactions between tonic alertness and voluntary temporal preparation affected the overall magnitudes of spatial orienting and the foreperiod effect in an opposing manner, such that the presence of both processes in Quadrant 1 resulted in underadditive magnitudes of spatial orienting and superadditive magnitudes of the foreperiod.

Together, these data (1) reveal important differences between attention effects elicited by social and nonsocial information, (2) expose the reasons for why previous studies using the cuing paradigm have failed to find differences in orienting between social and nonsocial cues, and (3) highlight the importance of the cuing task parameters in the measurement of spatial orienting and the resultant attribution of attentional control mechanisms. We now discuss each point in turn.

\section{Sensory-Specific Attention}

Our experiments show two main results indicating that social and nonsocial information engage attention in a cue-specific manner. First, social and nonsocial cues differ in their intrinsic alerting qualities. Second, orienting elicited by social and nonsocial information is differentially susceptible to the cue's typical link with an upcoming target event.

The cue's ability to engage attention quickly provides a strong test of its intrinsic alerting power. Our data show that rapid orienting elicited by gaze persisted in an equal manner when gaze direction provided no spatial or temporal information about the target, when the target overall appeared less frequently, and when the cue contained gaze information devoid from its typical face context speaks to the alerting power of gaze. However, the rapid engagement of attention by gaze was short-lived when the contribution of both task variables was reduced in Quadrant 4. This may reflect the usage of gaze cues in life, in that rapid orienting to gaze is initiated by its evolutionary importance while sustained orienting occurs when the gaze shift is deemed important for one's present behavior or when the task environment invokes a high frequency of overall target presentation and/or the development of an implicit expectancy of a response target (e.g., Quadrants 1-3). Thus, while we might follow gaze rapidly, we may continue to do so only when gaze direction is deemed relevant in some way, by, for example, conveying meaningful information about the response (such as providing timing information to signal an upcoming response event), signaling a potential social interaction, or revealing something important about an individual.
In contrast, the attentional effects of nonsocial arrows appear to be intimately tied with a target event. This mirrors the typical usage of symbolic cues in that they often provide relevant information for ongoing behavior that is coupled with a response event, such as when asking for directions or navigating an unfamiliar setting. Indeed, overlearning such relationships has been put forward as the explanation behind automated symbolic orienting (Ristic \& Kingstone, 2012; Ristic et al., 2012). Our results revealed that this behaviorally relevant link appears to be so strong that it continued to drive attention even in the absence of task induced cue-target aids (i.e., Quadrants 2 and 4$)$.

Thus, social and nonsocial cues affect attention in a sensory-specific manner, reflecting the way social and nonsocial information is typically used in life. This result extends recent discussions concerning the importance of a cue's selection history in spatial orienting (Awh, Belopolsky, \& Theeuwes, 2012; Ristic \& Landry, 2015) and highlights the idea that the human attention system is sensitive to contextual, motivational, and learning factors. Note that because these theoretical accounts argue that attention is recruited differentially as a function of the incoming sensory information, it is reasonable to expect that other types of attentional cues that have traditionally been used to elicit and measure attention within a cuing task (e.g., peripheral onsets, nondirectional symbols) may affect attention in yet a different manner depending on their typical usage in life, prior selection history, and/or type of required attentional control.

\section{Why no Dissociations Until Now}

As such, it follows from our data that the cue-specific effects of social and nonsocial information on attention have been masked in previous studies, which have utilized the cuing task with the typical parameter settings. Our results also reveal why, despite much theorizing to the contrary (Baron-Cohen, 1995; Birmingham et al., 2012; Nation \& Penny, 2008), previous investigations have found indistinguishable attentional effects for social and nonsocial cues using this task (Tipples, 2008). The answer lies in the differential contributions of the cuing tasks' extraneous processes to orienting elicited by social and nonsocial cues.

High tonic alertness (i.e., the presence of a response target on most trials), which affects a general readiness to respond, and present voluntary temporal preparation (i.e., the increasing probability of target occurrence with lengthening of cuetarget time), which affords the development of implicit temporal target contingencies, differentially affect spatial orienting elicited by social and nonsocial cues but in the end produce identical data - rapid and prolonged spatial orienting. While rapid orienting in response to social gaze emerges because of the cue's high alerting qualities, sustained orienting depends on the tasks' requirements, which in the typical cuing 
procedure involve a high frequency and predictability of target occurrence. In contrast, the typical rapid orienting that often is observed with spatially nonpredictive arrows (Ristic et al., 2002; Ristic \& Kingstone, 2006) may reflect the contribution of extraneous task variables, such as high tonic alertness or present voluntary temporal preparation induced either by the task parameters (Experiment 1) or by the cue's physical properties (Experiment 2), suggesting that nonsocial cues may require task aids to engage attention rapidly. The sustained effects of symbolic cues, on the other hand, likely reflects their selection history in that an arrow continues to be seen as a reliable indicator of a relationship between the behaviorally relevant stimulus and its utility for a particular target, response, or goal-directed action.

Implications for the Attributions of Attention Control

According to the classic notions then, the cue-specific effects of social cues, as revealed by the Quadrant 4 data might be considered to reflect automatic or reflexive attention while in contrast, the attentional effects elicited by symbolic arrows might be considered to require some voluntary control.

However, the extant literature on human attention points to difficulties in making such attributions unequivocally. This is because the classic division between involuntary and voluntary attentional control as well as the associated experimental markers of involuntary and voluntary attention have been developed based on data from a cuing paradigm (Berger et al., 2005; Posner \& Cohen, 1984), in which the specific contributions from the interactions between the extraneous processes of tonic alertness and voluntary temporal preparation have not been identified and accounted for. Furthermore, and in contrast to the common wisdom that tonic alertness, voluntary temporal preparation, and spatial orienting operate independently (as postulated by the recent ANT paradigm; Fan, McCandliss, Sommer, Raz, \& Posner, 2002; see MacLeod et al., 2010 for additional concerns regarding the ANT procedure), the present results as well as mounting evidence from other investigations (Callejas et al., 2005; Callejas et al., 2004) support the notion that tonic alertness and voluntary temporal preparation interact. Within the cuing task, it is likely that these interactions develop because an attentional cue indicates three events and engages three processes simultaneously - the target's potential location, affecting spatial orienting, the target's overall frequency of occurrence, affecting tonic alertness, and the target's probability of occurrence within each trial, affecting voluntary temporal preparation (Weinbach \& Henik, 2012).

Against this backdrop, it is apparent that the classic cuing task does not provide a measure of spatial orienting alone. Instead, the measure of attention is contaminated by the concurrent processes of tonic alertness and voluntary temporal preparation as well as by their interactions. We have shown here that the nature of those interactions depends on the characteristics of the attentional cue and the particular task settings, while existing data also indicate that those interactions may also differ as a function of the required response (e.g., target discrimination vs. target detection; Gabay \& Henik, 2008, 2010; Hayward \& Ristic, 2013a; Ristic \& Landry, 2015). Systematic investigations are needed to assess the contributions of tonic alertness and voluntary temporal preparation and their interactions to the measures of spatial orienting and the foreperiod effect elicited by the classic cuing task. The results of those studies will inform how these processes affect the performance profiles associated with involuntary and voluntary attentional control and will provide an unambiguous benchmark for the theoretical attributions of attentional control processes elicited by different types of sensory information.

Acknowledgments This research was supported by a graduate fellowship awarded to DH from the Natural Sciences and Engineering Research Council of Canada (NSERC), and by grant support to JR from NSERC, G.W., Stairs, Social Sciences and Humanities research Council of Canada (SSHRC) and William Dawson funds.

\section{References}

Alegria, J. (1978). Sequential effects of catch-trials on choice reaction time. Acta Psychologica, 42, 1-6.

Awh, E., Belopolsky, A. V., \& Theeuwes, J. (2012). Top-down versus bottom-up attentional control: a failed theoretical dichotomy. Trends in Cognitive Sciences, 16(8), 437-443.

Baron-Cohen, S. (1995). Mindblindness: An essay on autism and theory of mind. Cambridge, MA: Bradford.

Bateson, M., Nettle, D., \& Roberts, G. (2006). Cues of being watched enhance cooperation in a real-world setting. Biology Letters, 2, 412414.

Bayliss, A. P., \& Tipper, S. P. (2006). Predictive gaze cues and personality judgments: Should eye trust you? Psychological Science, 17(6), 514-520.

Berger, A., Henik, A., \& Rafal, R. D. (2005). Competition between endogenous and exogenous orienting of visual attention. Journal of Experimental Psychology: General, 134(2), 207-221.

Bertelson, P. (1967). Time course of preparation. The Quarterly Journal of Experimental Psychology, 19(3), 272-279.

Birmingham, E., Bischof, W. F., \& Kingstone, A. (2009). Get real! Resolving the debate about equivalent social stimuli. Visual Cognition, 17(6/7), 904-924.

Birmingham, E., \& Kingstone, A. (2009). Human social attention: A new look at past, present and future investigations. The Year in Cognitive Neuroscience, Annals of the New York Academy of Sciences, 118140.

Birmingham, E., Ristic, J., \& Kingstone, A. (2012). Investigating social attention: A case for increasing stimulus complexity in the laboratory. In J. A. Burack, J. T. Enns, \& N. A. Fox (Eds.), Cognitive neuroscience, development, and psychopathology (pp. 251-276). New York: Oxford University Press.

Boggia, J., \& Ristic, J. (2014). Social event segmentation. The Quarterly Journal of Experimental Psychology. doi:10.1080/17470218.2014. 964738 
Bonato, M., Priftis, K., Marenzi, R., \& Zorzi, M. (2008). Modulations of hemispatial neglect by directional and numerical cues in the line bisection task. Neuropsychologia, 46, 426-433.

Brignani, D., Guzzon, D., Marzi, C. A., \& Miniussi, C. (2009). Attentional orienting induced by arrows and eye-gaze compared with an endogenous cue. Neuropsychologia, 47(2), 370-381.

Callejas, A., Lupiáñez, J., Funes, M. J., \& Tudela, P. (2005). Modulations among the alerting, orienting and executive control networks. Experimental Brain Research, 167, 27-37.

Callejas, A., Lupiáñez, J., \& Tudela, P. (2004). The three attentional networks: On their independence and interactions. Brain and Cognition, 54, 225-227.

Corbetta, M., \& Shulman, G. L. (2002). Control of goal-directed and stimulus-driven attention in the brain. Nature Reviews Neuroscience, 3(3), 201-215.

Correa, A., Lupiàñez, J., Milliken, B., \& Tudela, P. (2004). Endogenous temporal orienting of attention in detection and discrimination tasks. Perception \& Psychophysics, 66(2), 264-278.

Correa, A., Lupiàñez, J., \& Tudela, P. (2006). The attentional mechanism of temporal orienting: Determinants and attributes. Experimental Brain Research, 169, 58-68.

Coull, J. T., Frith, C. D., Buchel, C., \& Nobre, A. C. (2000). Orienting attention in time: Behaviour and neuroanatomical distinction between exogenous and endogenous shifts. Neuropsychologia, 38, $808-819$

Csibra, G. (2010). Recognizing communicative intentions in infancy. Mind \& Language, 25(2), 141-168.

Dehaene, S., Bossini, S., \& Giraux, P. (1993). The mental representation of parity and number magnitude. Journal of Experimental Psychology: General, 122(3), 371-396.

Dodd, M. D., Van der Stigchel, S., Leghari, M. A., Fung, G., \& Kingstone, A. (2008). Attentional SNARC: There's something special about numbers (let us count the ways). Cognition, 108(3), 810 818.

Driver, J., Davis, G., Ricciardelli, P., Kidd, P., Maxwell, E., \& BaronCohen, S. (1999). Gaze perception triggers reflexive visuospatial orienting. Visual Cognition, 6(5), 509-540.

Emery, N. J. (2000). The eyes have it: The neuroethology, function and evolution of social gaze. Neuroscience and Biobehavioural Reviews, 24, 581-604.

Fan, J., McCandliss, B. D., Sommer, T., Raz, A., \& Posner, M. I. (2002). Testing the efficiency and independence of attentional networks. Journal of Cognitive Neuroscience, 14(3), 340-347.

Feigenson, L., Dehaene, S., \& Spelke, E. (2004). Core systems of number. Trends in Cognitive Sciences, 8(7), 307-314.

Fischer, M. H., Castel, A. D., Dodd, M. D., \& Pratt, J. (2003). Perceiving numbers causes spatial shifts of attention. Nature Neuroscience, 6 , $555-556$.

Folk, C. L., Remington, R. W., \& Johnston, J. C. (1992). Involuntary covert orienting is contingent on attentional control settings. Journal of Experimental Psychology: Human Perception and Performance, 18(4), 1030-1044.

Friesen, C. K., \& Kingstone, A. (1998). The eyes have it! Reflexive orienting is triggered by nonpredictive gaze. Psychonomic Bulletin \& Review, 5(3), 490-495.

Friesen, C. K., Ristic, J., \& Kingstone, A. (2004). Attentional effects of counterpredictive gaze and arrow cues. Journal of Experimental Psychology: Human Perception and Performance, 30(2), 319-329.

Frischen, A., Bayliss, A. P., \& Tipper, S. P. (2007). Gaze cueing of attention: Visual attention, social cognition, and individual differences. Psychological Bulletin, 133(4), 694-724.

Gabay, S., Avni, D., \& Henik, A. (2012). Reflexive orienting by central arrows: Evidence from the inattentional blindness task. Psychonomic Bulletin \& Review, 19, 625-630.

Gabay, S., \& Henik, A. (2008). The effects of expectancy on inhibition of return. Cognition, 106, 1478-1486.
Gabay, S., \& Henik, A. (2010). Temporal expectancy modulates inhibition of return in a discrimination task. Psychonomic Bulletin \& Review, 17(1), 47-51.

Galfano, G., Dalmaso, M., Marzoli, D., Pavan, G., Coricelli, C., \& Castelli, L. (2012). Eye gaze cannot be ignored (but neither can arrows). The Quarterly Journal of Experimental Psychology, 65(10), 1895-1910.

Gibson, B. S., \& Kingstone, A. (2006). Visual attention and the semantics of space: Beyond central and peripheral cues. Psychological Science, 17(7), 622-627.

Greene, D. J., Mooshagian, E., Kaplan, J. T., Zaidel, E., \& Iacoboni, M. (2009). The neural correlates of social attention: Automatic orienting to social and nonsocial cues. Psychological Research, 73(4), 499-511.

Hayward, D. A., \& Ristic, J. (2013a). Measuring attention using the Posner cuing paradigm: the role of across and within trial target probabilities. Frontiers in Human Neuroscience, 7(205). doi: 10. 3389/fnhum.2013.00205

Hayward, D. A., \& Ristic, J. (2013b). The uniqueness of social attention revisited: Working memory load interferes with endogenous but not social orienting. Experimental Brain Research, 231(4), 405-414.

Hommel, B., Pratt, J., Colzato, L., \& Godijn, R. (2001). Symbolic control of visual attention. Psychological Science, 12(5), 360-365.

Hopfinger, J. B., Buonocore, M. H., \& Mangun, G. R. (2000). The neural mechanisms of top-down attentional control. Nature Neuroscience, 3(3), 284-291.

Jonides, J. (1981). Voluntary versus automatic control over the mind's eye's movement. In J. B. Long \& A. D. Baddeley (Eds.), Attention and performance (Vol. IX, pp. 187-203). Hillsdale, NJ: Erlbaum.

Kingstone, A., Friesen, C. K., \& Gazzaniga, M. S. (2000). Reflexive joint attention depends on lateralized cortical connections. Psychological Science, 11(2), 159-166.

Klein, R. M., \& Shore, D. I. (2000). Relations among modes of visual orienting. In S. Monsell \& J. Driver (Eds.), Control of Cognitive Processes: Attention and Performance XVIII (pp. 195-208). Cambridge: M I T Press.

Kobayashi, H., \& Hashiya, K. (2011). The gaze that grooms: Contribution of social factors to the evolution of primate eye morphology. Evolution and Human Behavior, 32, 157-165.

Kuhn, G., \& Kingstone, A. (2009). Look away! Eyes and arrows engage oculomotor responses automatically. Attention, Perception, \& Psychophysics, 71(2), 314-327.

Kuhn, G., Tatler, B. W., \& Cole, G. G. (2009). You look where I look! Effect of gaze cues on overt and covert attention in misdirection. Visual Cognition, 17(6-7), 925-944. doi:10.1080/ 13506280902826775

Langton, S. R. H., \& Bruce, V. (1999). Reflexive visual orienting in response to the social attention of others. Visual Cognition, 6(5), 541-567.

Luck, S. J., Hillyard, S. A., Mouloua, M., Woldorff, M. G., Clark, V. P., \& Hawkins, H. L. (1994). Effects of spatial cuing on luminance detectability: Psychophysical and Electrophysiological evidence for early selection. Journal of Experimental Psychology: Human Perception and Performance, 20(4), 887-904.

MacLeod, J. W., Lawrence, M. A., McConnell, M. M., Eskes, G. A., Klein, R. M., \& Shore, D. I. (2010). Appraising the ANT: Psychometric and theoretical considerations of the Attention Network Test. Neuropsychology, 24(5), 637-651.

McKee, D., Christie, J., \& Klein, R. M. (2007). On the uniqueness of attentional capture by uninformative gaze cues: Facilitation interacts with the Simon effect and is rarely followed by IOR. Canadian Journal of Experimental Psychology, 61(4), 293-303.

Milliken, B., Lupiáñez, J., Roberts, M., \& Stevanovski, B. (2003). Orienting in space and time: Joint contributions to exogenous spatial cuing effects. Psychonomic Bulletin \& Review, 10(4), 877-883. 
Miniussi, C., Wilding, E. L., Coull, J. T., \& Nobre, A. C. (1999). Orienting attention in time: Modulation of brain potentials. Brain, 122, 1507-1518.

Mondor, T. A. (1999). Predictability of the cue-target relation and the time-course of auditory inhibition of return. Perception \& Psychophysics, 61(8), 1501-1509.

Näätänen, R. (1970). The diminishing time-uncertainty with the lapse of time after the warning signal in reaction-time experiments with varying fore-periods. Acta Psychologica, 34, 399-419.

Nätänen, R. (1972). Time uncertainty and occurrence uncertainty of the stimulus in a simple reaction time task. Acta Psychologica, 36, 492503.

Nation, K., \& Penny, S. (2008). Sensitivity to eye gaze in autism: Is it normal? Is it automatic? Is it social? Development and Psychopathology, 20(1), 79-97.

Nieuwenhuis, S., \& de Kleijn, R. (2013). The impact of alertness on cognitive control. Journal of Experimental Psychology: Human Perception and Performance, 39(6), 1797-1801.

Nobre, A. C. (2001). Orienting attention to instants in time. Neuropsychologia, 39, 1317-1328.

Okamoto-Barth, S., \& Kawai, N. (2006). The role of attention in the facilitation effect and another "inhibition of return". Cognition, 101, B42-B50.

Posner, M. I. (1980). Orienting of attention. The Quarterly Journal of Experimental Psychology, 32(1), 3-25.

Posner, M. I., \& Boies, S. J. (1971). Components of attention. Psychological Review, 78(5), 391-408.

Posner, M. I., \& Cohen, Y. (1984). Components of visual orienting. Nillsdale, NJ: Erlbaum.

Pratt, J., \& Hommel, B. (2003). Symbolic control of visual attention: The role of working memory and attentional control settings. Journal of Experimental Psychology: Human Perception and Performance, 29(5), 835-845.

Ristic, J., Friesen, C. K., \& Kingstone, A. (2002). Are eyes special? It depends on how you look at it. Psychonomic Bulletin \& Review, 9(3), 507-513.

Ristic, J., \& Kingstone, A. (2006). Attention to arrows: Pointing to a new direction. The Quarterly Journal of Experimental Psychology, 59(11), 1921-1930.

Ristic, J., \& Kingstone, A. (2012). A new form of human spatial attention: Automated symbolic orienting. Visual Cognition, 20(3), 244-264.
Ristic, J., \& Landry, M. (2015). Combining attention: A novel way of conceptualizing the links between attention, sensory processing, and behavior. Attention, Perception, \& Psychophysics, 77(1), 36-49.

Ristic, J., Landry, M., \& Kingstone, A. (2012). Automated symbolic orienting: The missing link. Frontiers in Psychology, 3(560). doi: 10.3389/fpsyg. 2012.00560

Ristic, J., Wright, A., \& Kingstone, A. (2006). The number line effect reflects top-down control. ;Psychonomic Bulletin \& Review, 13(5), 862-868. doi:10.3758/bf03194010

Ristic, J., Wright, A., \& Kingstone, A. (2007). Attentional control and reflexive orienting to gaze and arrow cues. Psychonomic Bulletin \& Review, 14(5), 964-969.

Sternberg, S. (1969). Memory-scanning: Mental processes revealed by reaction-time experiments. American Scientist, 57(4), 421-457.

Stevens, S. A., West, G. L., Al-Aidroos, N., Weger, U. W., \& Pratt, J. (2008). Testing whether gaze cues and arrow cues produce reflexive or volitional shifts of attention. Psychonomic Bulletin \& Review, 15(6), 1148-1153.

Tanaka, J. W., \& Farah, M. J. (1993). Parts and wholes in face recognition. The Quarterly Journal of Experimental Psychology Section A: Human Experimental Psychology, 46(2), 225-245.

Tipper, C. M., Handy, T. C., Giesbrecht, B., \& Kingstone, A. (2008). Brain responses to biological relevance. Journal of Cognitive Neuroscience, 20(5), 879-891.

Tipper, C. M., \& Kingstone, A. (2005). Is inhibition of return a reflexive effect? Cognition, 97, B55-B62.

Tipples, J. (2002). Eye gaze is not unique: Automatic orienting in response to uninformative arrows. Psychonomic Bulletin \& Review, $9(2), 314-318$

Tipples, J. (2008). Orienting to counterpredictive gaze and arrow cues. Perception \& Psychophysics, 70(1), 77-87.

Weinbach, N., \& Henik, A. (2011). Phasic alertness can modulate executive control by enhancing global processing of visual stimuli. Cognition, 121, 454-458.

Weinbach, N., \& Henik, A. (2012). Temporal orienting and alerting - The same or different? Frontiers in Psychology, 3(236). doi: 10.3389/ fpsyg.2012.00236

Weinbach, N., \& Henik, A. (2013). The interaction between alerting and executive control: Dissociating phasic arousal and temporal expectancy. Attention, Perception, \& Psychophysics, 75, 1374-1381. 